Insight, part of a Special Feature on Strengthening adaptive capacity

\title{
Integrating Sacred Knowledge for Conservation: Cultures and Landscapes in Southwest China
}

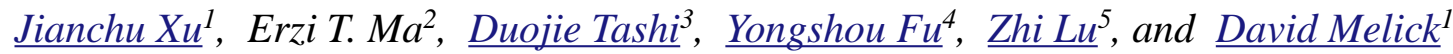

\begin{abstract}
China is undergoing economic growth and expansion to a free market economy at a scale and pace that are unprecedented in human history. This is placing great pressure on the country's environment and cultural diversity. This paper examines a number of case histories in China, focusing on the culturally varied and ecologically diverse southwest region of the country. We show how developments in recent Chinese history have devalued and in some cases eliminated indigenous knowledge and practices in the quest to strengthen the centralized state. Despite these changes, more than 30 ethnic minorities live in southwest China. For generations these peoples have maintained landscapes through traditional land use and cultural practices. This indigenous knowledge places a high value on protecting forests, landscapes, and water catchments while preserving biodiversity. These values are maintained through religious beliefs, hunting taboos, and the protection of sacred sites. We advocate a conservation policy for China that includes the indigenous knowledge and values needed to maintain the environment and the traditional cultures themselves. There are seminal signs that the government is beginning to support indigenous cultures in China. The Organic Law of 1998 granted villages the legal right to self-government and gave indigenous communities greater responsibility for land and resource use. Traditional and indigenous cultural products have also developed a market and an economic value within a growing tourism industry. In many cases, however, indigenous people remain isolated from major land-use and conservation decisions that are the result of centrally planned policy. Meanwhile, frequent oscillations in forest policy and land tenure insecurity since the 1950s have led to the erosion of many local institutions and the loss of indigenous knowledge. We suggest that the long-term viability of the environment requires an interactive approach that involves local people as well as governments in the creation of environmental policy. We also suggest that enlightened self-interest can help economic development coexist with the needs of traditional cultures.
\end{abstract}

Key Words: biodiversity; economic development; environmental degradation; ethnic minorities; indigenous knowledge; sacred knowledge; China

\section{INTRODUCTION}

With the rapid expansion of free market economies and the global breakdown of cultural and trade barriers, we need to pay attention to the uncertainties that face indigenous cultures in China as they strive to use, nurture, and sustain the diverse landscapes in which they live and upon which they depend. Among the most powerful contemporary forces shaping both local cultures and biodiversity are various government policies that aim to modernize, standardize, and scale up rural production as well as increase manufacturing to meet the demands of expanding regional, national, and international markets (Culture and Biodiversity Congress 2000). In the face of threats to local cultures, we need to document indigenous knowledge and practices. Most importantly, we need to enhance the capacity of indigenous people to strengthen evolving cultural traditions as well as improve their livelihoods and dignity. This will also help to conserve local biodiversity.

After a period characterized by repressive domestic policies in China, recent decades have seen the opening up and success of economic reforms. These have produced high and sustained economic growth

\footnotetext{
${ }^{1}$ Kunming Institute of Botany, Chinese Academy of Sciences, ${ }^{2}$ Liangshan Nationality Institute, ${ }^{3}$ Snowland Greatrivers Environmental Protection Association, ${ }^{4}$ Yunnan College of Art, ${ }^{5}$ Conservation International
} 
rates and lifted millions of people out of poverty. Concurrent political reforms have decentralized many decision-making processes and created new democratic institutions, especially in rural areas. This process has ceded new political powers and established new economic incentives. It has also transferred some of the power for managing natural resources to local entities (Xu and Ribot 2004). However, conflicts have emerged between the need to increase decentralization to enhance local livelihoods and the need to protect environmental services affecting larger populations. Increasing public awareness of deforestation and its links to soil erosion, loss of biodiversity, floods, and other forms of environmental degradation have made the protection of forest ecosystems a central government priority. Consequently, some of these conservation policy changes have placed additional stress on natural resources and on the livelihoods of indigenous communities in politically and economically peripheral areas.

To some degree, China's increasing desire to be part of the global community has forced the government to begin confronting its huge regional impact and responsibilities. Given the large changes occurring, the ecological health of southwest China concerns not only China itself but also the surrounding region. Improved communications and transportation as well as vast new infrastructure construction along the Mekong and Yangtze river systems threaten the ecosystems and the ethnic people in the region. Addressing these issues has spurred centralized decision making in terms of conservation policy.

As southwest China becomes more integrated into the market economy of China, Southeast Asia, and the world, cultural attributes such as diversity, indigenous knowledge, and skills become valuable social capital. This social capital benefits ethnic people, the state, and the region (Xu and Salas 2003). Ethnic peoples in the region are being increasingly viewed as important cultural resources and as potential sources of marketable products such as handicrafts, handmade papers, and costumes. Even traditional rituals, dances, and sacred places are being identified as possible new products (Coward 2003). Transforming traditional cultures into commodities in a market economy is a new phenomenon that has both positive and negative effects on cultural identity and the development of sustainable livelihoods. However, the activities of local people can be significantly strengthened by the incorporation of modern advances when assisted by research professionals, government and nongovernment organizations, and even the commercial sector to ensure the equitable and sustainable sharing of benefits (Posey and Dutfield 1996).

In this paper, we examine how indigenous practices have helped maintain cultural and biological diversity over centuries in China and how this knowledge may help improve the effectiveness of today's conservation policies by increasing their flexibility and local relevance. In contemporary society, technological advances and economic prosperity often come at great cost to social values. We recognize that some local groups and indigenous communities are more resilient to changes than others, and we are optimistic that many local groups can continue to shape and strengthen their cultural heritage and local biodiversity while making a transition to an emerging free market.

\section{A HISTORY OF EXCLUSION}

The richness of cultural diversity in China is undeniable. From the point of view of the state, ethnic minorities or marginalized populations are particularly significant: they live predominantly in frontier or geographically peripheral areas and therefore have a strategic role. Thus, the relationship between the state and local ethnic people directly affects internal and external stability (Herberer 2000). The state has paid attention to these peripheral areas because of the natural resources they contain and the land available for settlement. Consequently, China has a recent history of attempting to consolidate the state by the official inclusion of minority peoples. In many cases, however, these policies effectively repress minority rights and cultures.

In late Imperial China, ethnic inclusion policies adopted a strategy of filling the "strategic space" by bringing minorities more closely into the cultural and economic orbit of the center through resettlement (Menzies 1992). This strategy was continued after the People's Republic of China was founded, and policies toward ethnic people became intrinsically linked to national development efforts. The state used several methods to speed up the integration of minorities into the national state and to facilitate social transformation. For instance, from the hundreds of ethnic groups initially reported in Yunnan, only 25 were officially defined as 
minority nationalities. Nationwide, there are now a total of 56 officially recognized nationalities comprising 55 minority nationalities plus the majority Han Chinese. This official scheme for identifying ethnicity does not accurately reflect the diversity of Chinese cultures. Generally, the central planning economy during the collective period of 1950-1978 did not account for the variety of interactions between humans and the environment. This mindset is evident in much of the thinking on natural resource management that considers nature to be separate from culture.

In modern China, ethnic minorities still generally live on the geographical periphery. The dominant political and economic center is considered the "civilizing center" and is represented by the majority Han Chinese. This center has attempted to transform or "civilize" the peripherally located people on the ethnic frontiers. The center presumes that its own civilization, based on Han cultural values, is superior and may take upon itself a socalled noble commitment to uplift peripheral people (Harrell 1995, Xu and Salas 2003). Since new China was founded in 1949, the state has implemented numerous and sometimes conflicting policies affecting the ownership of land and cultural identity (Xu et al. 1999). Although the state government emphasizes ethnic equity and unity, the central state bureaucracy is dominated by Han Chinese who regard themselves as advanced in terms of economic and social development. They often consider the ethnic minorities to be backward and irrational. The policy makers in Beijing see China as a developmental state; one of the ultimate goals is to enhance the economy and living standards of people and to modernize the nation. Therefore, projects often move people from the uplands and settle them in the lowlands, forcing them to abandon livelihoods based on shifting cultivation and nomadic herding in favor of more sedentary lifestyles.

The state provides an organized structure and rules. It provides services such as roads and schools. It can be an agent of justice, and it can foster economic transformation (Evans 1996). In this case, the ability to transform people, land use, economies, and even landscapes becomes a source of legitimacy for the state.

Rather than include people, modern conservation policies in China generally deem the exclusion of people as necessary for the preservation of the landscape. They often blame indigenous people and their traditional ways of resource use for threatening biodiversity (Yin 2001). A pluralistic conservation approach, however, advocates a shift in attention away from the local people as the prime causes of the diversity crisis to the wider impacts of outside influences, namely megadevelopment projects, monoculture, and the consumption habits of urban people. This approach suggests an alternative method to conservation, moving from reductionist scientific knowledge to an inclusive system that empowers indigenous people to control and define their resource access. This approach also calls for a radical redefinition of the production and productivity of ecosystem goods and services away from the logic of uniformity and toward the logic of diversity (Escobar 1998).

\section{MOVES TOWARD A MORE INCLUSIVE SYSTEM}

Some policy makers are nervous about moving away from reductionist science to a more inclusive ecosystem approach. Ecologists, meanwhile, have long been struggling to create more inclusive ecosystem models. When Lovelock (1979) introduced the controversial "Gaia theory" of the earth as a self-regulating, complex superorganism, he recognized that ecosystem processes are linked and humans are a part of that system; we do not exist in isolation. In some ways, this broadscale interpretation of the environment and our place in it is reflected within indigenous communities and the way they manage their environment. In indigenous cultures, natural phenomena are often socialized, and social phenomena are described in ecological terms (Fairhead and Leach 1996). For instance, Tibetans perceive their sacred mountains as gods with human personalities.

The success of recent economic reform and a more relaxed political environment have aroused interest in cultural identity. They have also revived indigenous knowledge and religious practices in China. Hillman (2003) points out that China's minority nationalities, once the objects of pity and disparagement, have recently become objects of admiration. This change in attitude started in the 1980s with the growth of domestic tourism, and it grew during the ideological vacuum of the 1990s, when China, as a nation, began "searching for a soul." Moreover, Hillman (2003) makes the point that the state version of ethnicity is "... not a simple, singular or monolithic enterprise." Many 
government officials in minority areas are from diverse ethnic backgrounds themselves. Often the government officials who are the most responsive to policy change work at the township, county, and local levels. At these levels, they are not only aware of the realities of life but also cognizant of traditional spiritual values and practices.

Despite these changes, China is still struggling with many development issues. Since the 1980s, the economic gap between China's eastern or coastal regions and the western parts of the country has increased. In an effort to bridge this gap, the Beijing government adopted what it calls "the Great Western Development Strategy" in 2000. At the same time, the Yunnan provincial government was promoting Yunnan as a "Great Cultural Province" and a "Green Economy Province," focusing on its cultural and biological diversity. These policies promote ethnic cultures, as well as indigenous knowledge for the sustainable use of natural resources, as cultural assets for socioeconomic development. However, it seems to us that indigenous peoples are still generally treated as passive objects in central, state-dominated activities related to the use of natural resources, cultural preservation, and conservation.

\section{WHY INDIGENOUS KNOWLEDGE MATTERS FOR CONSERVATION}

For generations, indigenous people have lived in natural ecosystems in which they have developed and practiced life-styles and belief systems that draw upon their deep knowledge about local plants, wildlife, and ecology. Nevertheless, the local people with this knowledge are often unable to use it in a modern world in which state policy overrides local management. Increasingly, however, scientists and development planners are recognizing the importance of indigenous knowledge to biological resource management and the maintenance of biodiversity.

When discussing culture in this paper, we must distance ourselves from the classical Chinese definition of culture as it originates in Confucianism. This is a complex notion to translate, but in this sense culture or Wen hua means "literary transformation." It connotes a transformation to a higher form of civilization. This definition is significant because a Chinese view of culture plays a central role in the thinking behind many of the recent land-use and conservation policies in China.
In this paper, we define culture as the different ways in which people interact among themselves and with nature to generate original livelihoods, such as hunter-gatherers, paddy farmers, shifting cultivators, or nomadic herders. This variability in life-styles encompasses their world views, religious beliefs, knowledge, customary organizations, norms, and rules. Thompson et al. (1990) succinctly defined culture as the human process of the material transformation of nature as well as the collective creation of meaning about reality.

\section{Linking nature and biodiversity with indigenous cultures}

The current state of most, if not all, forests in China reflects many generations of cultivation and domestication. They have been cut, used, regenerated, managed, and reused many times for provisioning goods and regulating habitats. Forests that have not been exploited were either too difficult to access or protected for cultural reasons. Throughout history, forests and other ecosystems have supported Chinese society, providing goods such as food, game meat, fodder, organic fertilizers, timber, nontimber forest products including medicinal plants, and services such as soil formation, watershed protection, climate regulation, pollination, and the provision of habitats for animal and humans. In addition, forests have also supported a range of cultural services, including spiritual services, inspiration, aesthetic values, and places for recreation. The Millennium Ecosystem Assessment (2003) describes four broad categories of services that ecosystems can provide: provisioning services, regulating services, cultural services, and supporting services. These categories illustrate the diverse ways in which ecosystems contribute to human well-being. Despite, or perhaps because of, this long history of land use, China has been identified as a megadiversity country and one of the world's eight crop domestication centers (Vavilov 1992). Thus, China's forests can be considered to be not so much a product of nature per se but a product of culture.

If we are to maintain biodiversity in the landscape and forest ecosystems today, we need to recognize that these forests are present because of the actions of the local people who live in and around them. Biodiversity in China has been demonstrated to be part of complex historical interactions among biophysical and sociocultural systems over time 
(Sajise 1995). Traditional livelihoods that rely on indigenous knowledge concerning the use of fire, agriculture, technology, community forestry, and trade have been particularly powerful human influences on forest ecosystems (McNeely 1994). Protecting these areas by isolating them from people may destroy them and will certainly create resentment and resistance among those who have cultivated these forest landscapes for generations. Indeed, the term "protection" is not the most appropriate term for the objectives of forestry policy. As in agriculture, the objective is to optimize the use of these forests for values that include the conservation of habitat and endangered species as well as multiple uses at multiple scales. Conservation must be viewed as one among many important uses of both goods and services. Humanity's collective knowledge of biodiversity and its use and management resides in the diversity of cultures. By the same token, conserving biological diversity often helps to strengthen cultural integrity and values (McNeely 2000). Biodiversity, culture, and indigenous knowledge are interrelated and interdependent. Thus, how can conservation policy in China support one while accelerating the loss of the others?

\section{Resource use and indigenous livelihoods}

When advocating the incorporation of indigenous knowledge and livelihoods into conservation policy, it is relevant to understand the dichotomy that has developed between modern resource management and traditional land use in China. Livelihood can be considered a measure of the ingenuity of people to engage in dynamic, diverse, and complex activities for their subsistence needs and income generation in a particular political economic environment. Indigenous people care for a portfolio of activities. These activities are performed individually or at household or village levels. They take place over different time frames, ranging from days, weeks, and months to many years. Even shifting cultivators do not have one source of livelihood and often fish, hunt, and gather in diverse niches of different ecosystems. Thus, outsiders often fail to understand local survival strategies and tend to standardize or simplify complex systems into sector-based activities such as cash cropping, animal husbandry, and forestry. These simplistic classifications are evident in much of the land-use planning and policies in postrevolutionary China. This is reflected in the redirection of people to simpler sedentary livelihoods and/or their movement out of nature reserves in the interests of conservation.

The sustainability of the livelihoods of indigenous people is dependent upon several key issues. These people must be able to access natural capital, to adapt to changed environments and ecosystems, to access niches in the marketing chain, and to trade off between short-term and long-term goods and services. One salient example is the access by indigenous people to forests and to the markets for nontimber forest products (NTFPs). The role of outsiders is to assist local people in their reconstruction of emerging knowledge systems and the adaptation of strategies for interacting with large- and global-scale political economic realities. Until now, policies in China have steered indigenous people away from their traditionally flexible livelihoods, whereas new opportunities that are rooted in indigenous cultures and knowledge, such as NTFPs and cultural tourism, are often exploited by outside interests. The challenge is how to deal with the diversity of livelihoods and to find ways to support indigenous initiatives based on the specific livelihoods of each social group.

\section{SOCIETY AND LANDFORMS IN SOUTHWEST CHINA}

In this paper, southwest China refers to Yunnan, Sichuan, and Qinhai Provinces as well as the Tibetan Autonomous Region. Broadly, this mountainous area comprises three steps of descending terraced plateaus ranging from the high Qinghai-Tibet Plateau $(3000-5000 \mathrm{~m})$ in the northwest, through the Yunnan-Guizhou Plateau (1500-3000 m), to the valley basin $(<1500 \mathrm{~m})$ in the southeast. This region forms the headwaters of numerous important river systems, including the Yangtze (Jinsha), Mekong (Lancang), Salween (Nujiang), and Irrawaddy (Dulongjiang) Rivers. These rivers run southward, producing a system of long valley habitats at a variety of latitudes and altitudes. This variation is one reason why this region of southwest China supports a rich biological and cultural diversity. The region has been designated as a global biodiversity hotspot by a number of international conservation organizations (Mackinnon et al. 1996, Mittermeier et al. 2005). The diversity of ecosystems includes alpine habitats of glaciers, screes, and meadows above the tree line at or above $4000 \mathrm{~m}$, alpine conifer forest $(3000-3800 \mathrm{~m})$, deciduous forest (2600 
$3900 \mathrm{~m}$ ), oak forest (3000-4000 m), pine forest (2500-3500 m), mixed broadleaf forest, savannah (1000-2500 m), and riparian evergreen, broadleaf, and cedar forest $(<2800 \mathrm{~m})$.

Historically, southwest China was a remote frontier populated by a diversity of indigenous nomads who periodically moved their settlements, livestock, agriculture, and land-use practices. This region is home to more than $20 \times 10^{6}$ people from more than 30 ethnic groups (Harrell 2001a). The ethnic minorities of the southwest include (1) the TibetoBurman peoples, e.g., Tibetan, Naxi, Yi, Hani (Akha), Jingpo, Lisu, Lahu, Nu, Chang, Derung, Primi, and Jinuo, and (2) the Mon-Khmer peoples, e.g., Wa, Bulang, Deang, and Miao-Yao. The ethnic minorities in the region are characterized by complex dialects within groups and distinctive socioeconomic systems that reflect the region's biological complexity, including environments as varied as high-altitude alpine rangelands, dense tropical rain forests, and isolated river valleys. Strategies for maintaining rural livelihoods vary widely and include hunting and gathering, fishing, nomadic grazing, shifting cultivation, and intensive agriculture. There is a general trend toward pastoral grazing at high elevations, shifting cultivation and terraced agriculture at middle elevations, and intensive agriculture in the lower areas. These longterm variations in land usage have helped produce a mosaic of landscape patterns. In contrast to the rich natural biodiversity, human poverty is widespread in the region, and rural people face many uncertainties with respect to their livelihoods. These arise from government polices, transmigration, development interventions, and market expansion. Cultures are changing, and many biological resources are now vulnerable to depletion (Xu and Wilkes 2004).

These diverse landscapes and differing land uses have also contributed to cultural exchange throughout this region. Although marriages across ethnic groups are rare, interactions between ethnic groups do occur via transmigration, trading, and product flow, as well as through the sharing of resources and land. The famous trade routes, such as the ancient Tea-Horse Road that facilitates the exchange of Tibetan horses for Yunnan tea and the Southern Silk Road that links Central China to Southeast Asia, South Asia, and the Middle East can be traced back to 122 BC (Xu and Mikesell 2003). This long trading history has contributed significantly to economic prosperity and, more importantly, to cultural exchange in the region.

Southwest China also demonstrates an inextricable link between cultural and biological diversity that emerges from cultural and historic ties to mountain landscapes and ecosystems. The region hosts six of a total of 30 UNESCO heritage sites in China, including (1)

the Jiuzhaigou Valley scenic and historic area, (2) the historic ensemble of the Potala Palace in Lhasa, (3) the scenic and sacred Mount Emei, (4) the Leshan giant Buddha scenic area, (5) the old town and Dongba culture in Lijiang, (6)

Mount Qingcheng and the ancient Dujiangyan irrigation system, and (7) the three parallel rivers of Yunnan (UNESCO 2005).

\section{A TRAJECTORY OF SIMPLIFICATION: THE LOSS OF INDIGENOUS CULTURES IN CHINA}

China's process of ethnic identification in the early 1950s was heavily influenced by the needs of the newly forming state and its Stalinist conception of ethnicity (Fei 1980, Lin 1987, Harrell 1995, Keyes 2002). In addition to ethnic classification, an important part of the identification process was determining where each ethnic group would fit in the scale of history. For example, groups were classified according to whether they possessed primitive, slave-using, feudalist, capitalist, or socialist modes of production. This ethnic identification was followed by a state project known as "democratic reform," in which selected indigenous elites or leaders from the ethnic regions participated in building the state and creating autonomous regions. The local governments then carried out state-centric development plans, fulfilling the promise that all nationalities were equal "legally and morally" and thus would march together on the road to socialism. If some had farther to march than others, this was because of unequal historical progression up to the time of the Communist takeover (Harrell 1995). The development plans often included sending Han Chinese working teams to teach ethnic regions about advanced technologies for farming and management, to make shifting cultivation and nomadic pasture practices more sedentary, and often to resettle peripheral people in the lowlands (Sahlins and Scott 2001). This was thought to bring people closer to the central state that portrayed China as a multinational country of ethnic unity 
(Heberer 2000). During the Great Proletarian Cultural Revolution of 1966-1976, most of the stereotypical Soviet-style ethnological research ceased.

Over several decades, the combination of a centrally planned economy, resettlement, poor land-use practices, resource extraction from mountain regions, and more recent mass tourism developments has had major socioeconomic and ecological impacts on the indigenous communities in southwest China. Even in postreform times, the economic environment is uncertain because of frequent oscillations and seeming contradictions in land-use and land-tenure policies. Consequently, the intrinsic connections between nature and local communities have become fragile and threatened (Xu et al. 2004).

\section{Placement through plantation: the case of rubber plantations}

The state center in China, dominated by Han Chinese, defines not only the officially recognized ethnicities but also the land-use practices. Sedentarization has become a major developmental effort, particularly in the uplands of southwest China. This is well illustrated by the example of rubber plantations. During the collective period between 1958 and 1978, the People's Communes owned agricultural and forest lands. Land-use decisions, however, were not based on collective consent from within the commune but were administered through a centrally planned state quota system. During past decades, rubber plantations together with tea, sugar cane, and tobacco farming were considered to be the four pillars of industry in Yunnan. These contributed the lion's share of revenue for local governments. Rubber was the perfect crop. It helped socialist China become selfsufficient despite international embargoes. It helped upgrade the peasant-run agriculture-based production to the status of an industry. It helped to develop the "legible landscape" (Scott 1998) for the state. These new industries were also accompanied by an inflow of resettled Han Chinese to service and modernize the rural areas.

The widespread introduction of rubber plantations significantly affected local livelihoods by eroding the customary institutions, social networks, and rules governing indigenous upland communities. Tracts of forests were cleared. Watersheds were modified, and the traditional exchange of products was largely replaced by a centralized rubber market. In the areas in which rubber plantations were established, the local farmers had long practiced a composite swidden or a mosaic land-use system (Cuc 1995, Rambo 1995). This may have included a range of swidden-fallow fields, home gardens, fishponds, cash crop plantations, and even terraced rice paddies in upland areas. Furthermore, local farmers used a number of practices to enhance agrobiodiversity and forest regeneration. They did this by protecting useful species and forest seedlings, by planting favored native species such as rattan and bamboo during swidden fallow, and by domesticating native plants (Brookfield and Padoch 1994, Xu et al. 1999). Alcorn (1990) calls swidden farming "managed deforestation," a system that uses a patchy, pulsed removal of trees but does not remove the forest. From the state's perspective, however, a livelihood dependent on monoculture rubber plantations is much simpler to monitor and easier to control, and tax, than a livelihood that depends on traditional swidden agriculture and secondary vegetation ecosystems.

Attempts by the state to establish rubber plantations in southern China on an industrial scale were thwarted by the variable nature of the landscape and the microclimate. Thus, in southern China, large rubber plantations were often highly fragmented. In recent times, the economic viability of the large monoculture rubber plantations has diminished, and now most of China's rubber is grown by smallholder farmers, often as one of a suite of crops in mixed farming systems.

\section{Displacement through resettlement: the case of poverty alleviation}

Many ethnic people rely on a variety of activities for their livelihoods, including the harvest of forest products, shifting cultivation, and permanent agriculture. However, in many places, government officials consider these subsistence farmers to be backward and poor. Many indigenous people identified as being extremely poor were resettled to other areas after their villages were categorized as "remote and dispersed" or "unserviceable" and their environment classified as "inhospitable and uninhabitable" (D. X. Wang 2000). This pejorative labeling often made assumptions that linked environmental features and resource use patterns with levels of civilization as defined by Han 
Chinese. Thus, in recent years, Lisu people were resettled from the Salween River Gorge in northwest Yunnan Province to the temperate areas in Baoshan and the subtropical climates of Simao Prefecture. Reports suggest that the relocation to Simao, in particular, has had disastrous consequences for the settlers' standard of living, and they have failed to integrate into communities and society at large (D. X. Wang 2000). Moreover, this resettlement has negatively affected local environments in Simao as new arable land has been cleared. In Baoshan, the local government recently expressed its desire to return the settlers to the Nujiang.

The Kuchong people provide another example. Previously, the Kuchong were a group of nomadic hunter-gatherers who lived in the tropical forests of the Yunnan-Vietnam border region. They engaged in silent barter trade and had little contact with outsiders. The state identified their way of life with the "primitive communism" stage described in the Marx-Engels model of social evolution and have attempted to civilize the Kuchong people through a variety of initiatives. These interventionist programs included reclassifying the Kuchong as a branch of the sedentary Lahu people, building them permanent homes, training them to use chopsticks, and introducing them to fried foods (Huan et al. 2000). Sedentarization has had a significant impact on Kuchong resource use and their attitudes toward previously sacred landscapes. Research indicates that the Kuchong have transferred the sites of their worship of sacred mountains to new sites within their new areas of resettlement. However, their relation to these sacred places has changed. They have also adapted poorly to the new environment and the alien means of generating livelihoods. Social problems, including alcoholism, are prevalent in the community.

\section{Impacts of the Cultural Revolution}

Although Mao Zedong launched the Cultural Revolution of 1966-1976 to promote "thought reform" for urban-based and politically centered people, it has also had a profound impact on ethnic people in southwest China (Shapiro 2001). Indigenous knowledge and cultural beliefs were considered to be superstitious and backward. Local temples and monasteries were either closed or destroyed. Much ancient literature and many manuscripts about local cultures, religions, and indigenous practices were burned in public. All religious practices were forbidden, and religious practitioners were considered to belong to one of the "nine categories of bad people" and classified as "monsters and demons" and "forces of evil." The breakdown of religious practices and cultural beliefs resulted not only in a generational knowledge gap about cultural identity but also a loss of knowledge about resource use and management. Political chaos resulted in the destruction of both local authority and customary institutions, and this helped increase deforestation in the most mountainous and ecologically sensitive regions (Xu and Ribot 2004).

\section{Postreform political and conservation policy changes}

The economic liberalization initiated in the agricultural sector in 1978 was followed by the decentralization of resource management, including management of the forest sector in 1981. Village elections gained nationwide legal standing with a revised Organic Law of the Village Committee in 1998. This dramatically changed institutional landscapes in China ( $\mathrm{Xu}$ and Ribot 2004). A concomitant revision of the Forest Law in 1998 officially recognized the right to sell and transfer live stands of forest land. The Organic Law, while granting villages the legal right to self-government, also shifted the accountability of village leaders from township governments downward to village congresses. This allowed local communities as well as locally elected leaders, who often represent local ethnic groups and their intimate indigenous knowledge, to participate in decision making $(\mathrm{Xu}$ and Ribot 2004; H. Weyerhaeuser, K. Kahrl, and Y. $\mathrm{Su}$, unpublished manuscript).

Given these fundamental policy changes, institutions are now emerging at the local community level. These institutions are based on customary institutions but are formed in response to the emerging market economy. Villages are officially encouraged to make their own regulations for community resource management. Collective forest tenure has evolved into three overarching forms: household-managed responsibility hills and family hills, collectively managed plots, and shareholding. In practice, however, the ownership of collective land is unclear, and tenure insecurity remains a prime concern to village households. Although villages and townships are the legal beneficiaries of collectively owned forests, the 
ability of local people to benefit from them varies. Case studies in Yunnan Province (H. Weyerhaeuser, $\mathrm{K}$. Kahrl, and Y. Su, unpublished manuscript) show that this breakdown can sometimes be attributed to regulatory controls at higher levels of government. In other cases, it is due to institutional and social problems within the villages themselves.

The expansion of village rights and the autonomy of forest users have been paradoxically accompanied by an increase in forest regulation by the central level of government. In general, central policy overrides local concerns. The most significant recent changes in China's forest use occurred in 1998-2000 with the imposition of a ban on all logging in the upper reaches of river basins, known as the Natural Forest Protection Program. A second government program, the Sloping Land Conversion Program, requires that all farmland on slopes of more than 25 degrees be converted to forest or grassland. This latter policy included a scheme to supply food or cash compensation to affected households, the so-called Grain for Green program. Although the conservation aims of these policies are admirable, early research suggests that they may be not be mitigating erosion and surface flows as they were intended to do. Meanwhile, they are having negative impacts on the livelihoods of mountain communities, on their environment, and on overall agrobiodiversity (Weyerhaeuser et al. 2005).

\section{INDIGENOUS KNOWLEDGE AND PLURALISM IN CONSERVATION}

Given its high conservation value, southwest China has received attention from many international organizations concerned about environmental degradation (Xu and Wilkes 2004). Through a system of nature reserves and the recent ban on the logging of natural forests, China's government is actively supporting efforts to conserve the region's unique ecological and cultural landscape. Its aim is to protect the environment and to preserve the area's potential for generating revenue from tourism and bioresource extraction. However, this acknowledgement of cultural resources seems at odds with current conservation and land-use policy. Despite the fact that indigenous people have been living in the mountain regions for thousands of years as huntergatherers, pastoralists, and agriculturalists, they are often viewed by outsiders as objects to be managed rather than citizens in the mountain ecosystems. The local languages, indigenous knowledge, and religious practices linked to the worship of sacred spaces and the maintenance of biodiversity have already been extinguished in some places as a result of government policies, market penetration, migration, external education, and assimilation (Cox 1999, Sutherland 2003).

In China today, indigenous practices guided by their epistemology are essential to nurturing the interrelationship of nature and culture and to enhancing biological diversity ( $\mathrm{Xu}$ et al. 1999). Knowledge is a process involving the social construction of ideas about the external world that guide human action. Indigenous knowledge systems, locally rooted in a particular geography, are mostly culturally transmitted via collective memory that is encoded in stories, myths, legends, songs, dances, rituals, and practices. Indigenous knowledge can be common knowledge, such as knowledge about land-use or resource-use practices, and may be shared by the members of all the social groups within a community (Fig. 1). It may also be sacred or specialized knowledge known only to a few, such as religious leaders and herbal doctors. Examples are shamans (Bimo) in Hani and Yi societies, indigenous priests (Dongba) in Naxi society, or lamas among the Tibetans. These individuals act as intermediaries between the material and spiritual worlds.

Different ethnic groups in southwest China regard many landscapes as sacred (Pei and Luo 2000). A sacred landscape refers to sacred places such as mountains, hills, lakes, rivers, temples, shrines, etc.; sacred objects such as religious sculpture, stones, painting, hierograms, and costumes; living things that are considered sacred, including animals, individual plants, and forests; and sacred images of the supernatural. Sacred places are contextualized by the way they are expressed through material culture. Physically, a sacred place can vary from a few square meters to hundreds or thousands of square kilometers. It may hold significance for one household, a community, or multiple communities and ethnic groups. Sacred places are considered the source of powerful forces, energy, and wisdom. Sacred landscapes are maintained through the practice of religious rituals, ceremonies, and sanctions within a specific cultural group. The sacred ecology refers to the interactions between humans and nature in a particular landscape in this life and the next. Sacred ecology emphasizes that human beings are part of the ecosystem, and that all life is equal in terms of power, skill, and moral 
Fig. 1. In $1 \mathrm{~h}$, Tibetan villagers in northwest Yunnan collected more than 80 species of local plants used as medicines, food, fiber, etc. These have been used for generations and are classified within the village's epistemological and knowledge systems.

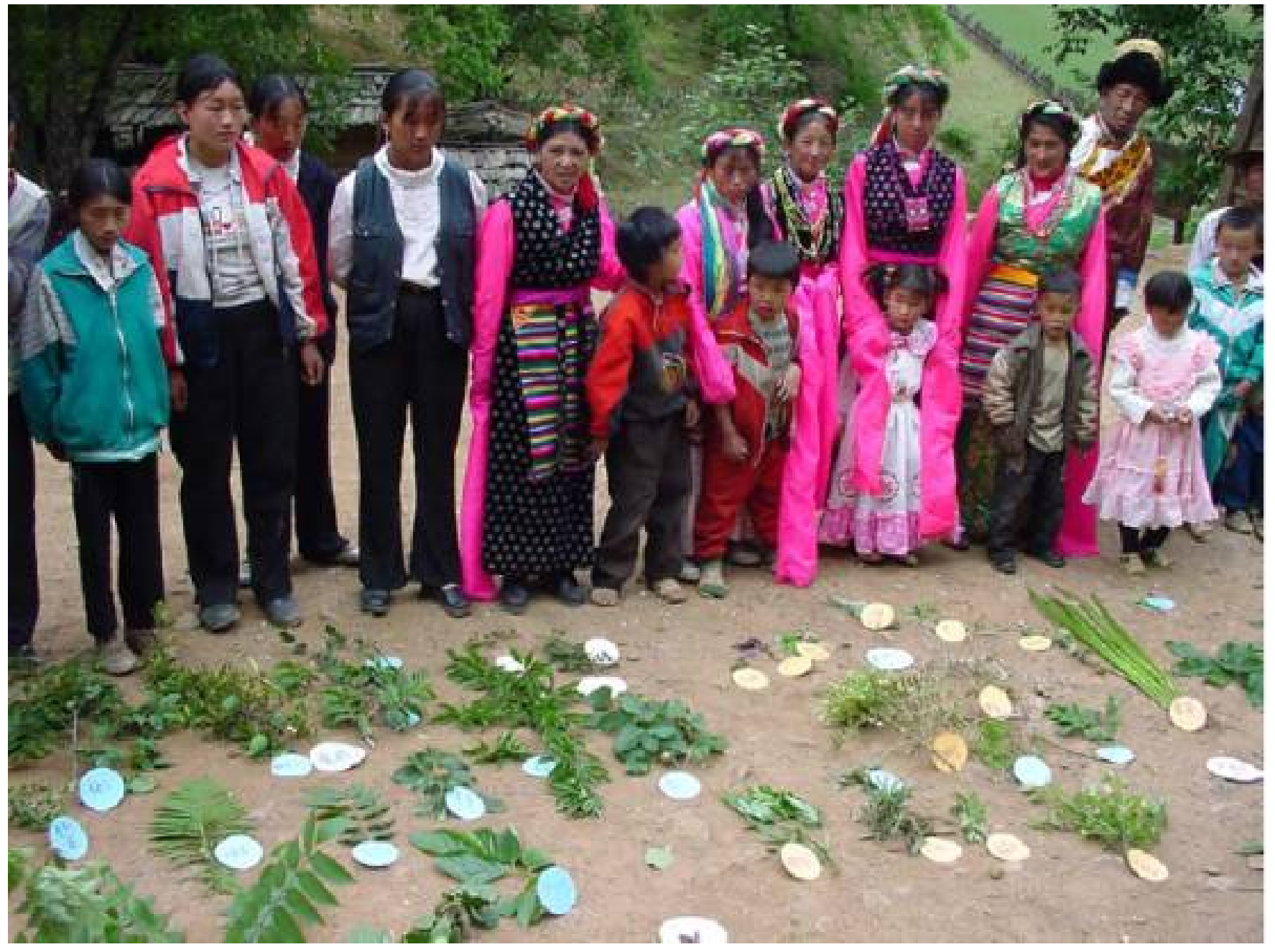

responsibility. Pluralism in ecology, therefore, may contribute to the preservation of sacred beliefs and the conservation of landscapes.

\section{EXAMPLES OF THE INDIGENOUS EPISTEMOLOGY OF NATURE}

The spirit of nature: the Naxi people's perception

The Naxi people worship the spirit of nature, Shu, as a spirit or god that governs nature. In illustrations, Shu has a human body with a snake's tail and wears a wubao, a hat with five treasures. In Naxi oral history, Shu and a human progenitor were once stepbrothers who shared the same father. When the two brothers went their separate ways, humans received valleys, crops, and domestic animals, whereas Shu received mountains, rivers, forests, 
birds, and wild animals. After that time, humans began to invade the property of Shu until the latter became very angry and decided to take revenge by making it difficult for humans to survive. Humans appealed to the Naxi priests and cultural specialists known as Dongba to control Shu. Eventually, Shu agreed that he and humankind would never harm each other again. Humans could obtain the necessities of life from nature, but they had to pay Shu by periodically worshiping him. This is the origin of the Shu worshiping ritual. Each year, people gather to worship Shu and pray for blessings for their children, for favorable weather for agriculture, for prosperity, and for the longevity of the community. People usually choose a water source or pond near the village as the site for the Shu worshiping ritual. The ritual involves various complex rites to banish evil and offerings representing, among other things, repayment for wood and traditional medicines.

The Shu worshiping ritual is a solution that the Naxi ancestors found to help reconcile their relationship with nature. It is a means of remembering their agreement with Shu. Humans can only ensure a good living environment and sustainable social development through self-discipline and by living in harmony with Shu. Water, forest, and land resources are cherished and can only be used with community and religious consent.

\section{The Dai people's holy hills and sacred water}

The Dai people live in northwest Vietnam, upper Laos, eastern Myanmar, northern Thailand, and southern Yunnan in southwest China (Hsieh 1995). According to Pei (1985), the valley-based Dai people in Xishuangbanna have practiced a predominantly Buddhist religion since the middle of the Tang Dynasty (AD 618-907). Before the introduction of Hinayana Buddhism, the Dai people apparently practiced a polytheistic religion linked to the natural world. Like many early groups, the Dai associated forests, animals, plants, and the forces of nature with the spiritual realm. Proper actions and respect for the gods were believed to result in peace and well-being. Improper activity and disrespect incurred the wrath of the gods, who punished the Dai villagers with a variety of misfortunes. Thus, the early Dai were encouraged to live in harmony with their surroundings through activities such as cultivating Cassia siamea trees for fuelwood in the foothills and maintaining religious plants in the temple yard. Moreover, harvesting timber species such as Cinnamomum comphora, $C$. glanduliferum, Paramichelia baillonii, and Gmelina arborea required the consent of a village committee. Other tree species such as Dysoxylum binectariferum growing upstream of the village were protected to maintain healthy water supplies (Yang et al. 2004).

In the Dai tradition, gods reside on the forested holy hills known in the Dai language as Nong (Pei 1985, Liu et al. 2002). All the plants and animals that inhabit these hills are either companions of the gods or sacred living things within the gardens of the gods. In addition, the Dai believe that the spirits of great and revered chieftains reside in the holy hills. Holy hills are a key component of local ecosystems that usually consist of paddy fields, home gardens, and cultivated fuelwood forest (Fig. 2). Holy hills appear to be classified into two types. The first, Nong Man, refers to a naturally forested hill that usually covers an area of 10-100 ha and is worshiped by a natural village known as a Man. The second, Nong Meng, refers to a much larger forested hill that often covers hundreds of hectares and is worshiped by a traditional administrative village or a governed area called a Meng. The traditional Dai practice of maintaining holy hills has made a significant contribution to the preservation of local and regional landscapes. Studies show a high concentration of endemic and endangered species in the holy hill forests. These include 15 species listed in the Plant Red Data List of China, such as Magnolia henryi, Homalium laoticum, and Antiaris toxicaria (Liu et al. 2002).

The government has started to recognize the wisdom of indigenous conservation methods and is moving to cultivate traditional Cassia fuelwoods and preserve remnant forests around Xishuangbanna. The recent expansion and rebuilding of Buddhist temples in the area has encouraged the reestablishment of temple gardens and the cultivation and preservation of a wide range of hardwood species, the so-called Buddha trees (Liu et al. 2002).

For the Dai people, however, water is arguably more important than land. Water is worshiped as the origin of life, and this is reflected in the Dai language. Water is called nan, and land is nanling. For centuries, the Dai people have tried to protect their environment and their traditional irrigation systems through a range of communal rules, institutions, and festivals. These included the appointment of village specialists in water 
Fig. 2. A landscape of a lowland Dai village in Xishuangbanna. The drawing shows a fuelwood forest of Cassia siamea trees on the left, a sacred forest or "holy hill" on the right, a temple yard garden in the background, and a home garden with residential areas and paddy fields in the foreground. Illustration by Yang Jiankun, Kunming Institute of Botany, Kunming, China.

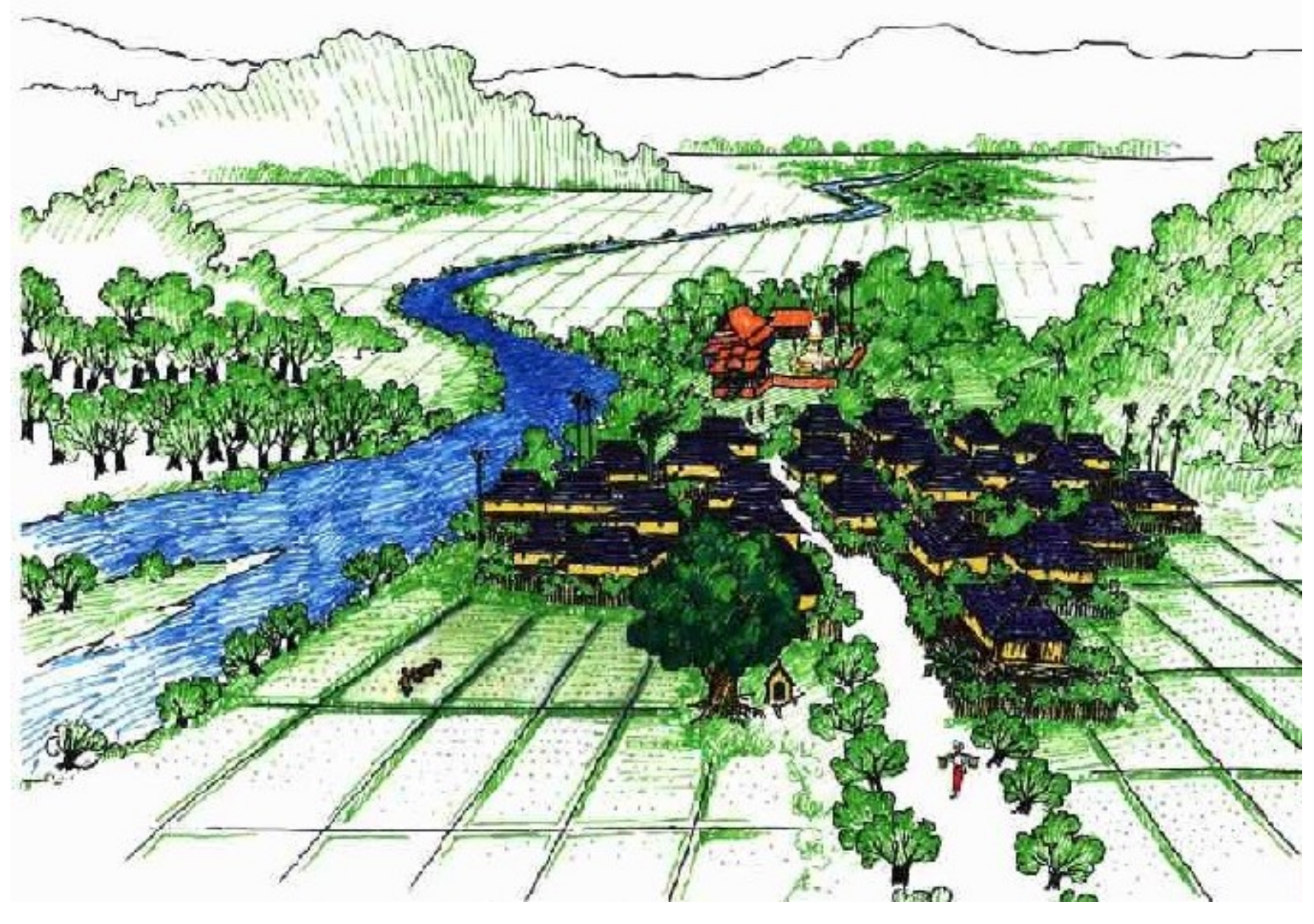

management, Banmen, who were responsible for distributing water and organizing the communal building and maintenance of dams, channels, and fishponds. Cooperation between the people of the uplands and those of the lowlands for the use of streams was encouraged and maintained through the intermarriage of people from neighboring regions, e.g., people in present-day Xishuangbanna and those in northern Thailand, who shared similar environments and religious beliefs ( $\mathrm{Xu}$ and Salas 2003).

These ancient management systems have been severely disrupted since the 1950 s because of the establishment of large state-run rubber plantations. Today, watershed governance remains a serious issue, and many analysts suggest that the best solutions require a return to collaborative systems that incorporate traditional values and agreed-upon community management (Ratner 2000). 
Fig. 3. The physical layout of a Hani village reflects the community's beliefs. Areas for human habitation are alongside outer areas of forest preserved for the souls of departed ancestors and gods. The village gate in the foreground separates society and nature, while the common house, in the center behind the gate, allows communication among the different facets. Illustration by Yang Jiankun, Kunming Institute of Botany, Kunming, China.

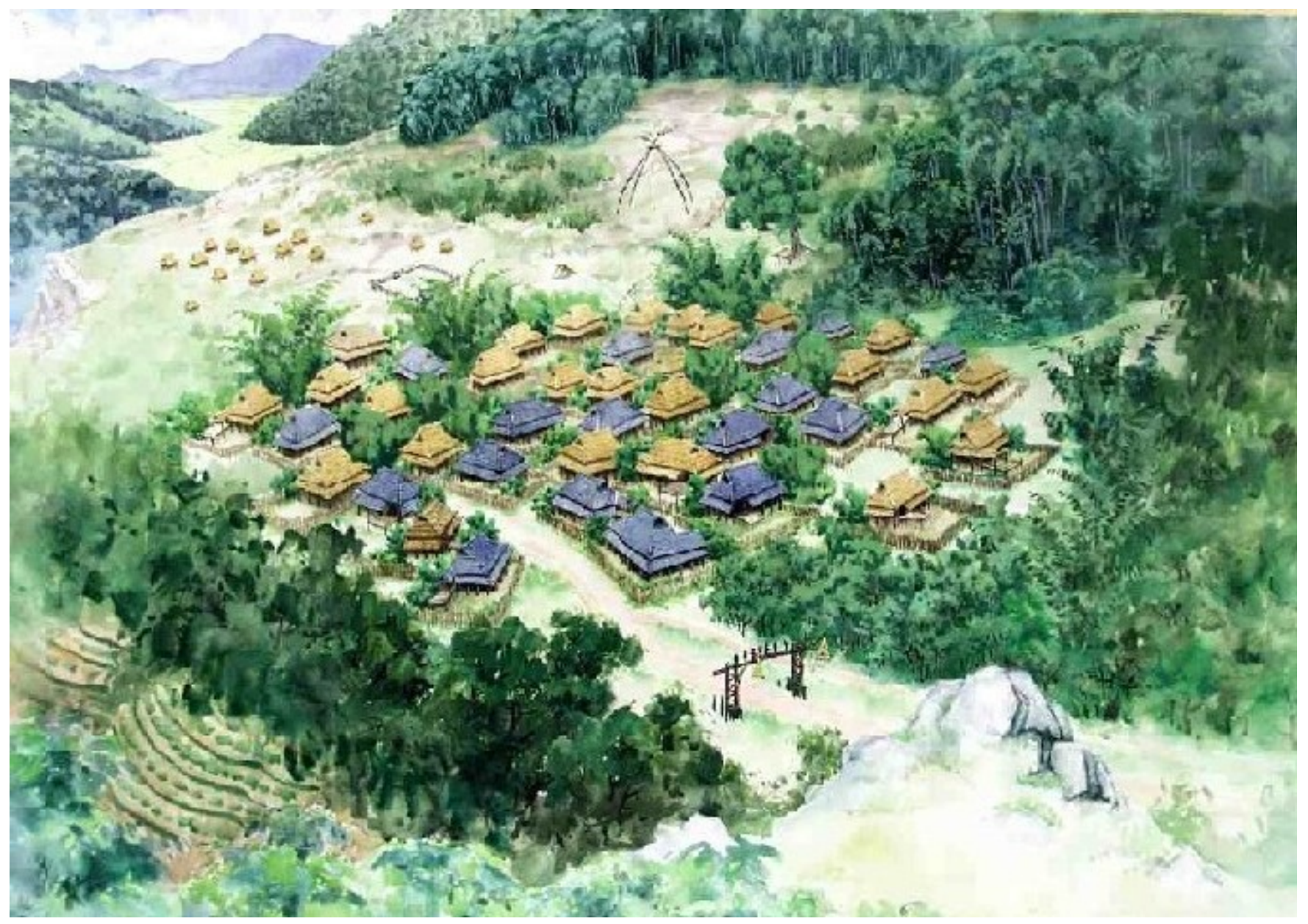

\section{The Hani concepts of village and nature}

About $1.25 \times 10^{6}$ Hani people live in Yunnan Province. The Hani are originally from the Tibetan Plateau. $\mathrm{Ha}$ means snow, strong, and brave. $\mathrm{Ni}$ suggests the people wholive in mountains. The Hani are thus a strong, brave, and mountain-dwelling people (Ma 1983). The Hani have a tradition of preserving forests in the mountainous areas in which they live. As an ethnic group residing primarily in southern Yunnan and bordering northern parts of Myanmar, Laos, Vietnam and Thailand, the Hani have kept harmonious relations with their natural surroundings for many centuries. Forest and watersheds are preserved by village consent. According to Hani cultural beliefs, humans are a part of the natural world in which everything has its own spirit. Most of the spirits repose in forests. Human activities such as collecting forest products, hunting, and cutting trees in these forests are taboo for Hani villagers (Xu et al. 1999).

The integral role of the forest to Hani culture is illustrated in the layout and nomenclature of their 
villages. A Hani village (Fig. 3) is surrounded by a village protection forest, called pucang, that is several hundred meters wide. This is divided into an inner human-inhabited place, also called pucang, and an outer, natural, nonhuman world known as baolcang. The word $p u$ means village and cang means place or forest. Thus, the term pucang refers to a forest or place for human residence or living. Baolcang, by contrast, refers to the wild, nonhuman world of spirits and gods. The village gate or lanlkang separates these human and nonhuman worlds. There is also a cemetery forest, laoqbiml, in which ancestors reside. Hani people believe that different spirits have their own habitats, such as wetlands, lakes, stones, or particular trees. The latter may include jhalna trees, Terminalia myriocarpa. The mother of the earth who governs all the gods related to agriculture is often represented by a big, strong, and long-lived tree such as an oak, Castanopsis mekongensis, or a bo tree, Ficus religiosa, in the village's sacred forest. These are often referred to as dragon trees (J. H. Wang 2000).

Central to Hani culture are those who hold traditional knowledge about cultural history and the environment. The Bimo or shaman generally commits knowledge going back more than 60 generations to memory. He recites all the ancient oral traditions about the origin of the Hani, the history, the migrations, the plant and animal cycles, and other natural phenomena. The Nipa is another type of shaman who diagnoses illnesses and communicates with spirits for advice about treatment, which often combines rituals, dancing, and medicinal plants. The continuation of these beliefs and practices in Hani culture has helped to preserve ethnobotanical knowledge and forest environments in areas in which the Hani live, and this is a subject that is seeing renewed scientific interest.

A clear example of a cultural practice that is still in use is the Hani protection and cultivation of rattan for the manufacture of traditional rattan furniture and baskets. The community rattan forests are known as sangpabawa, which translates to mean "the headmen's rattan forest." These have been protected as community property by indigenous people for about 12 generations through customary institutions established by Hani communities in Xishuangbanna. The traditional protection of rattan in the wild led to innovative practices of domesticating and cultivating rattan in the swidden fields (Xu et al. 1999). The practice has an ecological function because cultivating rattan in swidden-fallow fields results in improved fallow management and enhanced biodiversity. Moreover, rattan cultivation and production has social and cultural value through the exchange of rattan handicrafts between communities during the rattan "swinging festival" and as wedding gifts. The government and the forestry office have recognized the value of these practices within the society and therefore encourage their continuation ( $\mathrm{Xu}$ and Mikesell 2003).

\section{Tibetan sacred mountains: concepts of space and life}

The Tibetan people have named and classified spaces into internal and external worlds. The internal world or human community resides in the village. The people name each piece of land and each house on that land and adopt the name of the house as a family name. The external world beyond the house wall consists of arable lands, grazing rangelands, wild lands, lakes, and forest lands with plants, trees, fish, rocks, wildlife, etc. Sacred objects such as incense-burning podiums, pagodas, and mani stones function as places for Tibetans to dialogue with life and spirits in the external world. The graveyard is considered a transitional place between early life and transcendence into the "world of the death." This world is an external world that is controlled by spirits.

In Tibetan culture, life is a nonmaterial cycle with no beginning and no end. Humans must cultivate wisdom, and the behavior of a person determines his or her next life. The form of life is cause and effect. Humans are intrinsically a part of nature and biodiversity. A belief in reincarnation is part of Tibetan culture, and this has played a major role in the preservation of plants, animals, and the environment. It is not uncommon for people to have a close association with nature because they believe nature is directly linked to their departed kin (Fig. 4).

For generations, Tibetans in northwest Yunnan have lived a seminomadic existence, moving their livestock seasonally. Livestock are central not only to their life-style but also to their identity. Nomadic wandering and communal management are intertwined with a Tibetan sense of the environment. The grasslands are not merely something to be exploited but part of a wide-ranging spiritual landscape (Williams 2002). 
Fig. 4. A chough sits on a Tibetan widow's shoulder. The local people believe that the bird is the reincarnation of the woman's daughter. [ Erratum]

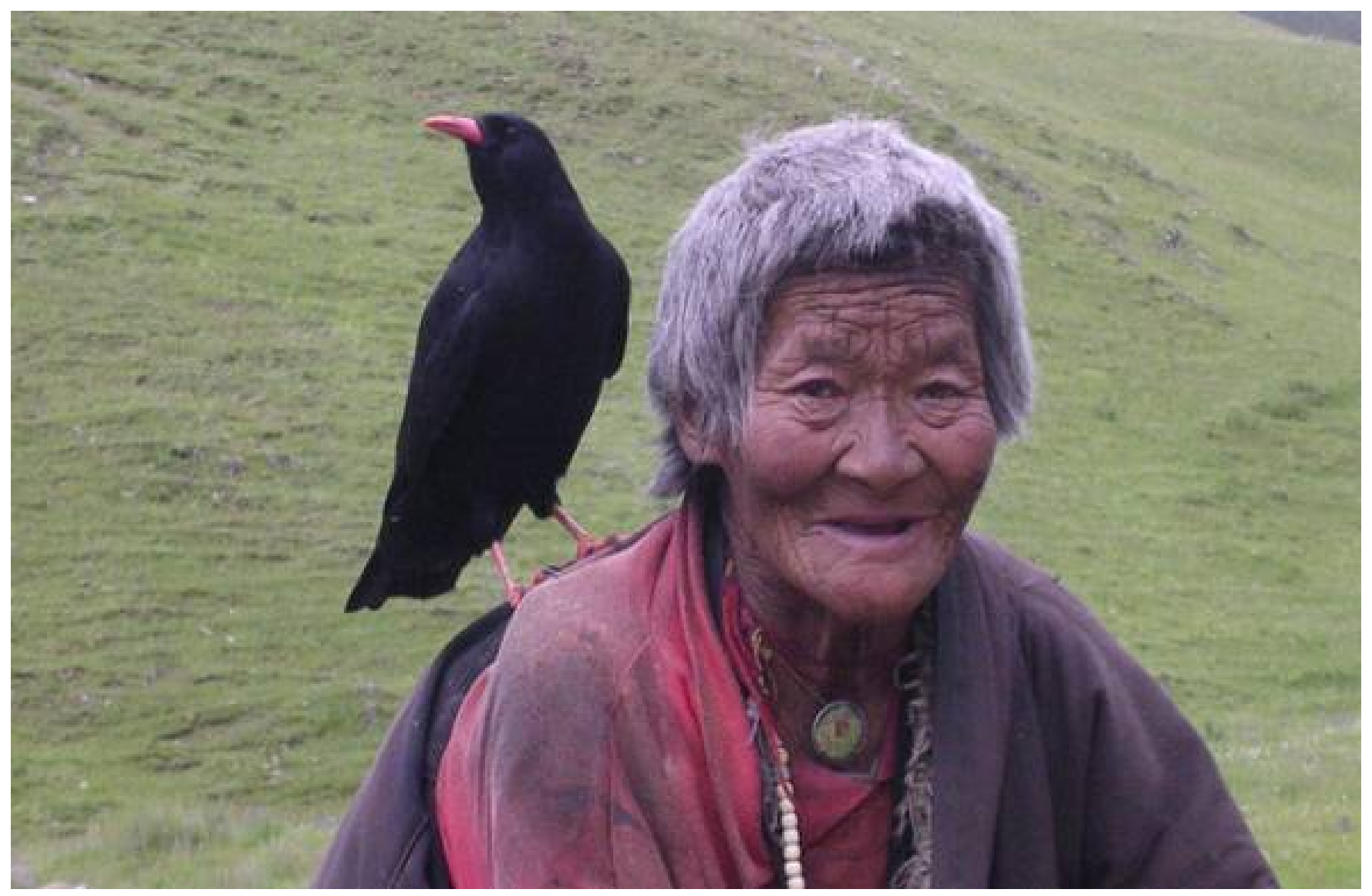

Recently, however, policy changes aimed at improving rural wealth by increasing the quality and quantity of livestock have encouraged sedentarization. Fencing programs have tried to limit the seasonal use of rangelands and instead have encouraged the use of silage and controlled breeding. In addition, the imposition of burning bans has removed a traditional method by which herders used to maintain local grasslands. These innovations have not been very successful in Yunnan, where many fences are neglected, supposedly protected pastures are illegally grazed, and attempts to encourage farmers to increase livestock numbers are leading to concerns about overgrazing and weed infestation in some alpine rangelands. These problems are obvious, and officials with the Forest Management and Animal Husbandry Bureau are now showing a renewed interest in working with stakeholders to develop sustainable systems using traditional management rules and practices, such as communal rotational grazing and regenerative burning.

Tibetan peoples are high mountain dwellers, and mountain worship is the most characteristic cultural belief and practice. The spread of Buddhism on the Qinghai-Tibetan Plateau imbued the Tibetan sacred mountains with new significance. For Tibetan people, the scale of the mountain is important (Guo 2000). Songre is a little peak designated for a spirit with small shrines but no residential houses; such a peak is worshiped only by a small village or one or two families. Nieda or Reda (some use the words interchangeably) is a whole mountain. It is bigger than Songre, and its worship is shared by larger village communities within a small region. People 
may live on it, although some Tibetan communities view such a mountain as very spiritually sensitive. Nieqian or Niere is a holy mountain highly regarded by the Tibetan community at large. These are also entire mountains. Nieqian is a term of respect, and the local name for Mt. Everest is Nieqian Qomolangma.

The protected spaces around sacred mountains are expansive because Buddhist lamas believe that bigger areas are less likely to be disturbed in a manner that would upset the spirits. This has obvious conservation benefits. Many areas in the Himalayas have suffered from stream pollution, severe erosion, and the overexploitation of forests for firewood. Sacred areas are largely protected from such overuse. In northwest Yunnan, local Tibetans believe that mountain gods residing on the peaks govern the land, animals, and people. There are more than 15 sacred mountains in the region, including the Meli Snow Mountain or Khabadkapo. This is the highest peak in Yunnan and is considered sacred by local Tibetans as well as all believers in Mizong Buddhism, one of the most important sects of Tibetan Buddhism. Khabadkapo is $6740 \mathrm{~m}$ high and covers an area of more than $200 \mathrm{~km}^{2}$. It is ranked as one of the eight most important sacred mountains on the Tibetan Plateau (Guo 2000). This sacred peak has never been climbed. In 1991, a joint JapaneseChinese expedition was mounted against the wishes of the local people. The deaths of 17 climbers, whose bodies were never recovered, was seen by many Tibetans as confirmation that man has no place on holy slopes. Each year, thousands of believers from Yunnan and other parts of the Tibetan region make a pilgrimage to the mountain. Some lamas are concerned that rapidly opening some of these areas to tourism might result in the destruction of sacred places. In recognition of the power of indigenous beliefs to protect the environment, some Tibetans lamas have designated religious names to sites in an attempt to prevent them from being disturbed. Government policy has also started to recognize local Tibetan beliefs, and access to many of these regions is restricted or prohibited. Protection of the area near Khabadkapo has been proposed by local government and conservation groups because of the geographic relationship between biodiversity patterns and the traditional conservation system of Tibetan sacred mountains.

\section{The Yi people's spiritual landscape}

The Yi people have a population of $6.6 \times 10^{6}$ and traditionally live in the provinces of Yunnan, Sichuan, Guizhou, and Guangxi of southwest China (China State Census Bureau and State Nationality Commission 2003). They believe that humans and wildlife are both offspring of the snow clan. The snow clan's offspring fall into 12 categories; six have blood, e.g., frogs, snakes, hawks, bears, monkeys and humans, and six do not, e.g., a group of local plants including cypress and poplar, fir, black-head grass, and sedges. In the Chuxiong Yi Prefecture of central Yunnan, local people believe that humans survived calamities with the help of these plants and animals. Others plants and animals are associated with gods or spirits. Recent surveys conducted in this prefecture show that at least 21 plant species are widely worshiped and protected by local Yi communities who adhere to various cultural beliefs (Liu et al. 2000). Historically, the $\mathrm{Yi}$ are animists. Their religion is based on ancestor worship, and they believe in many gods. They worship the spirits of the hills, trees, water, earth, sky, wind, and forests.

The Yi people have a long history of migration, and genealogy is very important to them. The Yi believe that, after death, their souls travel back to the origin of the Yi people to find peace. A person's genealogy is cited during funeral rituals, and each generation is linked to particular places and times along the historical migration routes. Songs and recitations of genealogical trees include references to the forest, the land, rivers, animals, and other environmental features at each place in which ancestors have lived. The souls of the dead must pass each of these places to return to their origins (Fig. 5). Each place marked along the ancestral migration path corresponds to a physical location. Thus, the Yi regard the landscape as being not only a visual form but also a part of language, practice, and ritual (Hirsch 1995). The Yi map of this spiritual and historical migration route is embedded in the collective memory. Singing the genealogy during rituals transports the Yi back across time and space and maintains ancient knowledge. Conservation of the environment is important because it harks back directly to their shared history. 
Fig. 5. The Yi genealogical tree can be traced back 80 generations. Each generation links to a particular place and time on the map of historical Yi migration routes from their origins in Zhaotong, northeast Yunnan Province.

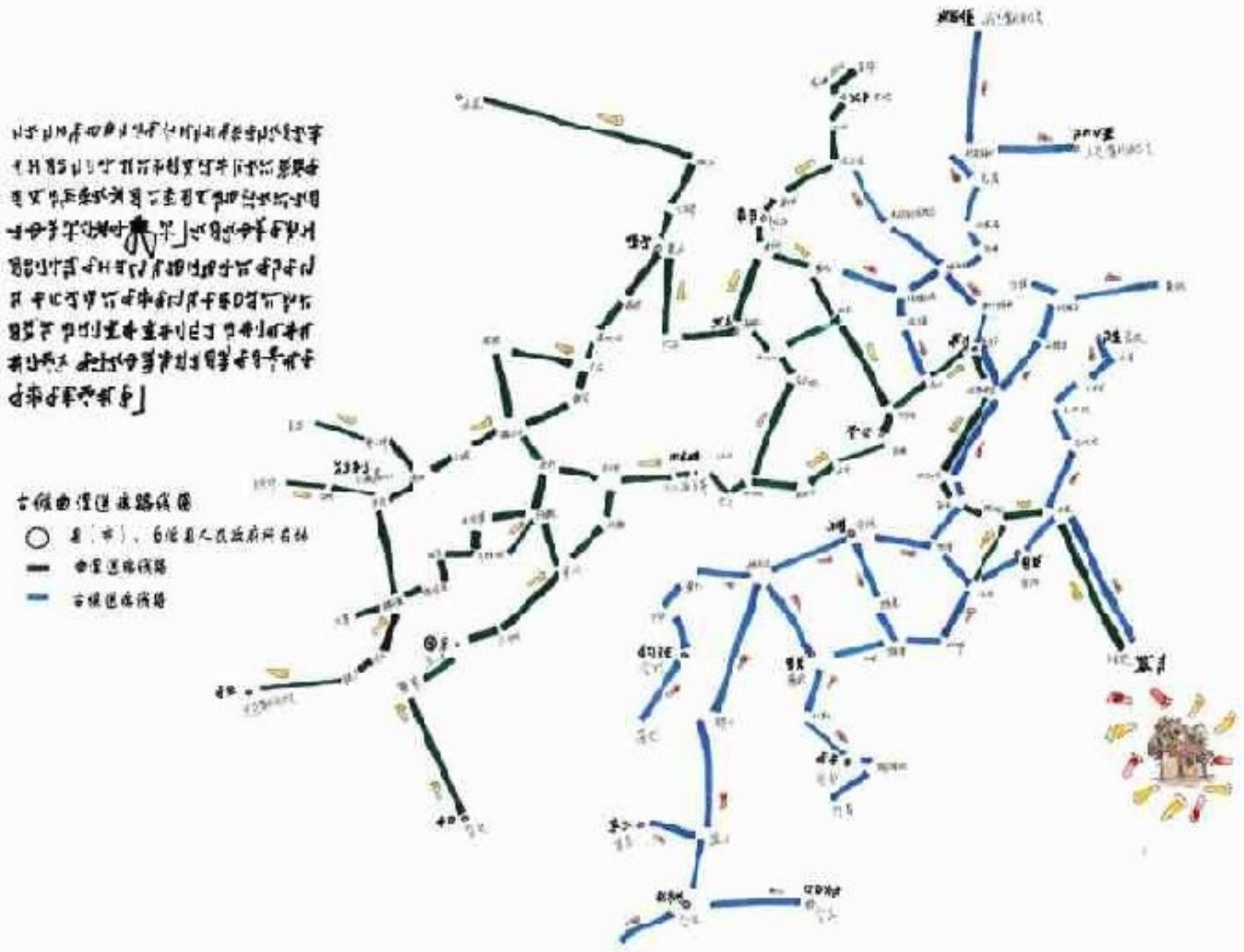

\section{DISCUSSION}

\section{Developing an appreciation of indigenous knowledge}

The relationship between natural resources and people has been forged within religious, moral, cultural, political, economic, and ecological boundaries. Respect for these boundaries by different communities and social groups is the result of historically accepted rules and norms. For the Dai and Hani people of Xishuangbanna, the forest- and water-oriented philosophy and the religious basis of traditional life have instilled a respect for forests, watersheds, plants, and animals. They have imbued these societies with accepted values and rules. The traditional world view and cultural beliefs of the Naxi, Dai, Hani, Tibetan, Yi, and other minorities in southwest China, combined with indigenous strategies for managing natural resources, have succeeded in preserving landscapes in this region. These people have effectively managed biological diversity within their environment over a long time. 
Timber trees have been protected and were harvested only with village consent. Upstream vegetation was preserved, and rangeland grazing was monitored by the community. These are examples of the positive impact of these traditional societies on the environment and on the conservation of biological diversity. Sadly, the drive to establish large, state-run farms and industries has often ridden roughshod over many of these cultural institutions. For example, rubber, tea, and sugar cane plantations in southern Yunnan and the logging industry in northwest Yunnan have cleared many of the forests within the mosaic landscapes that had been preserved by local people and their cultural beliefs. The worship of holy hills by the Dai or watersheds and superspiritual forests by the Hani has frequently been regarded as superstitious and suppressed by the state.

Forest policy in China offers a salient example of why it is necessary to use and foster traditional relationships between people and their land. Although there is now greater autonomy for villages to manage their own forests, they are still subject to central policy. This central control may have unintended environmental impacts. Case studies from Naxi and Miao communities in northern Yunnan show that villages often have little understanding of how to interpret overarching policy that often seems illogical and contradictory. For example, rules often restrict efforts to thin and improve forest structure, and there is a frequently a lack of clarity about household allowances for timber and firewood. This often leads to frustration and a disregard of rules and forest management policies altogether. This inevitably results in the degradation of forests (Taveau and Wang 2005; $\mathrm{H}$. Weyerhaeuser, K. Kahrl, and Y. Su, unpublished manuscript). Similarly, recent reforestation programs have been less effective because the policies intended to encourage reforestation have not been cooperatively developed with local communities. Much to the bemusement of local people, government departments have commonly replanted mixed conifer forests in northwest Yunnan with only a few centrally supplied species such as Abies georgei, Pinus densata, and $P$. yunnanensis. Unsurprisingly, many of these plantings have been unsuccessful. In areas in which these trees have become established, the diminished species richness has made these forests susceptible to widespread and devastating attacks by pests $(\mathrm{Xu}$ and Wilkes 2004). Along with failing to produce good timber for future use and security, these plantations are not particularly good habitats for other forest resources such as nontimber forest products (NTFP). It seems remarkable that community involvement and the use of indigenous knowledge in forest propagation were not encouraged and put into practice in these areas.

At the local level, some encouraging, albeit small, signs indicate that governments are beginning to heed customary wisdom. In some cases they are supporting traditional practices such as rattan and fuelwood cultivation. In others, governments are making tentative moves away from the push to sedentary livestock management and encouraging the preservation of culturally and environmentally sensitive regions. Governments have also been behind a recent shift away from large, unsustainable monoculture rubber plantations toward smaller mixed agroforestry systems. The fractious field of watershed governance is another area in which there is growing recognition of the need for community support and for acknowledging traditional boundaries and rules. This is a difficult issue that is often complicated by transborder concerns. Large increases in population and in land use require flexibility and readjustments to policy making (Ratner 2000, Igbokwe et al. 2003).

Recently, the traditional views of ethnic minorities regarding the universe and the world have been increasingly recognized as an important cultural resource with significant implications for environmental management and livelihoods (Bebbington 1999). At the same time, the Yunnan provincial government recently launched policies intended to transform Yunnan into a "Great Cultural Province" and a "Green Economy Province." Earlier policies supported the development of tourism in ethnic minority areas, whereas the new policies promote bioprospecting, among other things. In some cases in which the traditional knowledge of resource use is linked to the production of crafts, bioprospecting and the development of tourism products are related. In the transition to a market economy, culture and indigenous practices have come to be considered exotic and profitable instead of backward. These valuations of cultural resources have been defined by outsiders, including both powerful state authorities and entrepreneurs.

Following decades during which the central state discouraged ethnic cultural beliefs and practices, the indigenous peoples in southwest China are once 
again able to follow or revive these central elements of their cultures. They are combining their social and natural capital in fresh ways to respond to the expanding market opportunities and threats that are inherent in globalization. The commercialization of culture and indigenous knowledge has also raised a set of issues concerning intellectual property rights. For instance, can traditional knowledge be patented or protected? Would secret knowledge have to be divulged to obtain a patent? A growing number of workshops and training sessions in indigenous communities now include marketing and an introduction to basic legal rights.

\section{Indigenous knowledge in a changing environment}

Among the many things we can learn from indigenous knowledge and indigenous people is how to move from a reductionist to a systemic view of the world that includes our own diversity as part of the ecosystem. Recent changes in China have shown and are continuing to show that attempts to force idealized management models on diverse cultural and ecological systems often fail because of a lack of flexibility and understanding. The failure involves not recognizing the value of protecting forests and watersheds by means of existing community institutions and locally controlled logging, not maintaining small-scale mixed farms in contrast to large-scale monocultures, and not recognizing the traditional values of the flexible management practices that nomads use to manage livestock rangeland in marginal lands instead of government-dictated rules and enforced enclosures.

There is growing awareness that management policies and research must be more inclusive of local beliefs and institutions, using both customary authority and elected village committees to help implement policy. This is becoming apparent as the deficiencies of the heavy-handed centralized conservation measures are exposed. Watershed problems, desertification, and biodiversity loss are all the result of recent land-use changes. Many of these problems are of concern throughout the region. For instance, rangeland management to combat desertification is a priority throughout central Asia and northwestern China (Williams 2002), whereas watershed management is becoming critical in Southeast Asia with more intensive land use and increasing environmental degradation and poverty (Ratner 2000). A fundamental part of encouraging the use of indigenous knowledge is, of course, the sense of place and ownership. Land tenure and security is a clear priority for all governments with indigenous communities.

Given the excess of past exploitation, there is a new appreciation of indigenous knowledge and livelihoods. Traditional systems demonstrate their value in the modern world by the increasing market for NTFP and by the rise in ethnic tourism and associated products. In China and in northwest Yunnan, in particular, ethnobotanists and phytochemists are involved in international research to elicit traditional knowledge and identify potentially useful species. For example, recent treatments for HIV-AIDs and malaria involve plants found in this region (see Kunming Institute of Botany 2005, Missouri Botanic Garden 2005). Moreover, ethnic identity itself is now a saleable commodity as are traditional handicrafts. This commercial value not only facilitates the preservation or resurrection of traditional knowledge but also fosters greater local conservation of the necessary natural products and environments. A challenge now is to ensure that these potential benefits enrich local communities rather than outside interests. There are clear examples of outsiders attempting to dominate and hijack the ethnic tourism and NTFP markets in northwest Yunnan (Hillman 2003, Li 2003, Xu and Wilkes 2004)

This renewed interest in indigenous cultures has both positive and negative implications. On the one hand, ethnic tourism can serve as a force for cultural regeneration. There has certainly been renewed interest within minority cultures in Yunnan in terms of cultural emblems, handicrafts, and the rediscovery of traditional scripts, languages, and architecture (Hillman 2003). Similarly, after Lijiang, the home of Naxi people, was designated as a UNESCO cultural heritage site, more and more rituals have been revived and performed for the benefit of tourists. The Naxi scholars and local government have made efforts to establish mentorship and training programs for young people to learn sacred knowledge and religious rituals from living Dongba. Traditional rituals practiced by Dongba priests eventually become important activities for their own festivals and also motivate community-driven conservation practices in many Naxi communities (Yang 2003). The tourismdriven demand for handmade paper and traditional 
Naxi hieroglyphic script has revived this almost lost practice and has made it necessary to carefully plan the sustainable management of the endemic stringbush (Wikstroemia lichiangensis) that produces the required raw materials (Xu and Salas 2003).

The new opportunities afforded by market awareness of traditional products and tourism may lead, however, to the abandonment of traditional management practices. For instance, the commercial collection of mushrooms, animals, ornamental, and medicinal plants is a growing environmental concern in many parts of southwest China (Xu and Salas 2003, Xu and Wilkes 2004, Yang et al. 2004). Indigenous communities are also just as susceptible to nepotism and corruption as any other society when exposed to the opportunities provided by rapidly developing capitalism. This has been exemplified in Tibetan communities in which attempts to develop community-supported ecotourism have been laced with difficulties (Li 2003). The inclusion of local communities in resource allocation and policy making must be handled carefully and tactfully. In addition, ethnic tourism runs the risk of destroying or altering that which it seeks to preserve. Hillman (2003) uses the example of the shift in the motifs on handicrafts away from traditional images to more sexually provocative designs of minority women that appeal to Han tourists.

It is important to realize that local knowledge is not necessarily static, pristine, and culturally specific; it is dynamic and continuously evolving. As alluded to above, ethnic identities as well as group networks are changeable. This change may be both positive and negative and is influenced by cultural variation, rising populations, market opportunities, and sudden policy shifts. With the advent of large-scale logging in northwest Yunnan, for instance, many Tibetan and minority peoples eagerly capitalized on this resource and serviced the booming market. However, the sudden imposition of the commercial logging ban several years ago has forced communities to look to other revenue sources, namely tourism and NTFP. This has made Tibetan communities rediscover their traditional values, such as the importance of maintaining a balance with nature. In northwest Yunnan many ex-loggers lament the days when timber was recklessly cut and now take fresh pride in their primary and rehabilitating forests and natural scenery (Hillman 2003, Xu and Ribot 2004).
The inability of some indigenous communities to enforce their own ecological knowledge systems was evident in a comparative examination of villages in Lijiang conducted during the period of forestry market deregulation in 1985 . In some cases, the household allocation of forest land in villages produced disastrous results. New economic incentives gave rise to breakdowns in social order, with reports that "villagers ventured into the forest to log at night, fearful that their neighbours would cut the remaining forests" $(\mathrm{H}$. Weyerhaeuser, K. Kahrl, and Y. Su, unpublished manuscript). In the face of market pressures, efforts by some village leaders to enforce these rules proved ineffective. However, other villages subject to many of the same market pressures were able to maintain their forests because of their historically strong social cohesion and solid leadership (H. Weyerhaeuser, K. Kahrl, and Y.Su, unpublished manuscript).

More generally, the role of women in many cultures highlights some of the complexities of adapting and incorporating traditional values into a developing world. The legal rights and protections afforded to women since modern reforms have been generally applauded, but well-intentioned attempts by governments to assist rural communities may in reality be downgrading the role of women. For example, many training programs require people to be absent from the villages, making participation virtually impossible for women with children. Men also tend to be more literate, and male-dominated committees make numerous village decisions. This is not simply a gender equality issue; women can have a very significant effect on preserving biodiversity and agrodiversity because they are often the most actively involved with cultivation and resource management within households and communities. For instance, women are often responsible for collecting fuels and NTFP, drawing water, overseeing the sowing of fields, and managing the animals (Foggin and Smith 1996, Wang and Chen 2003, Xu and Salas 2003). In the search for employment in urban areas, male migration out of communities has become widespread, and many women are now the de facto heads of households, managing forests and farms. Empowering women and recognizing their importance is a theme that is becoming more important in many participatory development and conservation projects in China. 


\section{How to revive and incorporate indigenous knowledge}

Efforts should be made to close the knowledge gap between scientists and indigenous specialists by encouraging more extensive and intensive interaction between them in the field. To make this possible, the indigenous knowledge of local specialists must be documented, and scientists must obtain relevant training. Since China's reform policies began in 1978, anthropological studies in the nation have revived (Harrell 2001b). Scholars from a range of ethnic groups have been trained in cultural anthropology, ecology, social sciences, and interdisciplinary research. These scholars have helped to document indigenous knowledge and have facilitated cultural exchanges. They have encouraged indigenous innovation and initiatives for cultural revival. Many of these anthropologists and sociologists also participate in policy planning aimed at economic and cultural development in ethnic regions.

Many Naxi scholars have been developing ethnic schools and textbooks of indigenous knowledge, particularly as it relates to biodiversity and the environment, for community-based education within local communities (Yang 2003). Similar activities have also been implemented in Tibetan, Naxi, and Hani communities in Yunnan by the nongovernment Center for Biodiversity and Indigenous Knowledge and in $\mathrm{Yi}$ areas of Sichuan province by Stevan Harrell. Local county education bureaus have actively participated in these projects, helping to produce textbooks and expand programs. The production of the textbooks is directly contingent upon collecting and articulating indigenous knowledge as well as identifying who within a village is the best source of this knowledge. By identifying the local environmental specialists, it is possible to integrate them into group-based support systems. Such group-based systems can become strategic contacts for external agents of change such as governments, the media, or other interest groups. In another example, local Tibetan experts recently registered their own nongovernment organization called the Khabadkapo Tibetan Culture Center in northwest Yunnan. This group uses photography or photo voices of their own cultural expressions to help identify and revive indigenous knowledge.

Of course, incorporating indigenous knowledge and experience into policy requires the continued growth and sophistication of local government. The first steps in this direction were taken with the introduction of the Organic Village Law. However, there now appear to be increasing struggles between local governments, at both the county and township levels, and emerging community entities over decision-making powers. Thus, improvements to local elections and democratic processes are essential for conservation policy changes. Also needed is a clear articulation of legal and land tenure rights and responsibilities. Ecological accountability inevitably declines with the loss of a sense of place and land ownership. This is an area in which the indigenous people's respect for religious or sacred ecological values has in some cases maintained a sense of environmental responsibility even through extremely repressive government policies. The challenge of environmental and cultural management is not unique to China, but given China's diversity, its huge impact on the region, and its rapid growth, this is certainly an area that warrants further investigation and action.

Responses to this article can be read online at:

http://www.ecologyandsociety.org/vollo/iss 2/art7/responses/

\section{Acknowledgments:}

The field research upon which this paper is based was supported by the GTZ-BMZ project in Support of Indigenous Knowledge for the Use and Conservation of Biodiversity in Three Ecological Regions of southwest China. It was also supported by the Critical Ecosystem Partnership Fund Project on Applied Ethnoecology for Biodiversity Assessment, Monitoring and Management in northwest Yunnan and the Knowledge Innovation Program of the Chinese Academy of Sciences. We also acknowledge the contribution of the American Council of Learned Societies Collaborative Research Network. The authors also thank to the Ford Foundation, Beijing Office, and the Millennium Ecosystem Assessment (MA) for supporting the participation of the Chinese panel at the MA Conference on Bridging Scales and Epistemologies: Linking Local Knowledge with Global Science in Multi-Scale Assessments, Alexandria, Egypt, March 17-20, 2004. The authors also wish to thank Stevan Harrell for his valuable comments. 


\section{LITERATURE CITED}

Alcorn, J. 1990. Indigenous agroforestry strategies meeting farmers' needs. Pages 141-148 in A. Anderson, editor. Alternatives to deforestation: steps toward sustainable use of the Amazon Rain Forest. Columbia University Press, New York, New York, USA.

Bebbington, A. 1999. Capitals and capabilities: a framework for analyzing peasant viability, rural livelihoods, and poverty in the Andes. International Institute for Environment and Development, London, UK.

Brookfield, H., and C. Padoch. 1994. Appreciating agrodiversity. Environment 36:6-45.

Coward, E. W. 2003. Beyond characteristic crafts and distinctive dress: current views of ethnic identity with implications for upland resource management. Pages 331-340 in J. C. Xu and S. Mikesell, editors. Landscapes of diversity: proceedings of the III Symposium on MMSEA, 25-28 August 2002, Lijiang, China. Yunnan Sciences and Technology Press, Kunming, China.

Cox, P. A. 1999. Will tribal knowledge survive the millennium? Science 287:44.

China State Census Bureau and State Nationality Commission. 2003. China nationality census in 2000. Nationality Press, Beijing, China.

Cuc, L. T. 1995. Swidden agriculture in Vietnam. Pages 104-119 in Proceedings of the Symposium on Montane Mainland Southeast Asia in Transition, Nov. 12-16, 1995. Chiang Mai University, Chang Mai, Thailand.

Culture and Biodiversity Congress. 2000. The Yunnan initiative: visions and actions for the enhancement of biological and cultural diversity. Center for Biodiversity and Indigenous Knowledge, Kunming, China.

Escobar, A. 1998. Whose knowledge, whose nature? Biodiversity, conservation and the political ecology of social movements. Journal of Political Ecology 5:53-82.

Evans, P. 1996. Government action, social capital and development. World Development 24:1119-1132.
Fairhead, J., and M. Leach. 1996. Misreading the African landscape: society and ecology in a forestsavannah mosaic. Cambridge University Press, Cambridge, UK.

Fei, X. 1980. Ethnic identification in China. Social Science in China 1:94-107.

Foggin, M., and A. T. Smith. 1996. Rangeland utilization and biodiversity on the alpine grasslands of Qinghai Province, People's Republic of China. Pages 247-258 in P. J. Schei, S. Wang, and Y. Xie, editors. Conserving China's biodiversity II. China Environmental Science Press, Beijing, China.

Guo, J.2000. A mountain of nature, also a mountain of divinity: indigenous knowledge about the space of Mt. Khabadkarpo. Pages 230-239 in J. C. Xu, editor. Links between cultures and biodiversity: proceedings of the Cultures and Biodiversity Congress 2000, 20-30 July, Yunnan, China. Yunnan Sciences and Technology Press, Kunming, China.

Harrell, S. 1995. Civilising projects and the reaction to them. Pages 3-36 in S. Harrell, editor. Cultural encounters on China's ethnic frontiers. University of Washington Press, Seattle, Washington, USA.

Harrell, S. 2001a. Ways of being ethnic in southwest China. University of Washington Press, Seattle, Washington, USA.

Harrell, S. 2001b. The anthropology of reform and the reform of anthropology: anthropological narratives of recovery and progress in China. Annual Review of Anthropology 30:139-161.

Herberer, T. 2000. Some considerations on China's minorities in the 21st century: conflict or reconciliation? Institute for East Asian Studies Working Paper Number 13. Duisburg University, Duisberg, Germany.

Hillman, B. 2003. Paradise under construction: minorities, myths and modernity in northwest Yunnan. Asian Ethnicity 4:175-188.

Hirsch, E. 1995. Landscape: between place and space. Pages 1-30 in E. Hirsch and M. O'Hanlon, editors. The anthropology of landscape: perspectives on place and space. Clarendon Press, Oxford, UK. 
Hsieh, S. 1995. On the dynamics of Tai/Dai Lue ethnicity. An ethnohistorical analysis. Pages 301-328 in S. Harrell, editor. Cultural encounters on China's ethnic frontiers. University of Washington Press, Seattle, Washington, USA.

Huan, H. Y., J. C. Xu, and S. J. Pei. 2000. Ecological conservation practices and the cultural adaptation of the Lahu and Hani in Jinping, Yunnan, China. Pages 934-940 in J. C. Xu, editor. Links between cultures and biodiversity: proceedings of the cultures and biodiversity congress 2000, 20-30 July, Yunnan, China. Yunnan Sciences and Technology Press, Kunming, China.

Igbokwe, K. N., M. B. Espineli, X. Yu, and K. Lazarus. 2003. Toward developing and implementing a multi-stakeholder capacity building program for participatory watershed management: a case of Lashi watershed, Yunnan Province. Pages 359-372 in J. C. Xu and S. Mikesell, editors. Landscapes of diversity: proceedings of the III Symposium on MMSEA, 25-28 August 2002, Lijiang, China. Yunnan Sciences and Technology Press, Kunming, China.

Keyes, C. 2002. The peoples of Asia: science and politics in the classification of ethnic groups in Thailand, China and Vietnam. Journal of Asian Studies 61:1163-1203.

Kunming Institute of Botany. 2005. Ethnobiology and resource management projects. [online] URL: http://www.kib.ac.cn/KIBEnglish/soft/85.htm.

Li, B. 2003. Obstruction to local governance in natural resources management-a case study in Jisha Village northwest Yunnan. Pages 277-285 in J. C. $\mathrm{Xu}$ and $\mathrm{S}$. Mikesell, editors. Landscapes of diversity: proceedings of the III Symposium on MMSEA, 25-28 August 2002, Lijiang, China. Yunnan Sciences and Technology Press, Kunming, China.

Lin, Y. H. 1987. Ethnic identification in the southwest region of China. Pages 1-5 in Yunnan Editor Group, editors. Collection of materials from historical and sociological investigations of minority nationalities in Yunnan. Yunnan People's Press, Kunming, China.

Liu, A. H., S. G. Pei, and S. Y. Chen. 2000. An investigation and study on the plant worship in Chuxiong, Yunnan. Chinese Biodiversity 8:130-136.
Liu, H.M., Z. F. Xu, Y. K. Xu, and J. X. Wang. 2002. Practice of conserving plant diversity through traditional beliefs: a case study in Xishuangbanna, southwest China. Biodiversity and Conservation 11:705-713.

Lovelock, J. E. 1979. Gaia: a new look at life on Earth. Oxford University Press, Oxford, UK.

Ma, Y. 1983. A brief introduction to Yunnan's history. Yunnan People's Press, Kunming, China.

Mackinnon, J., M. Sha, C. Cheung, G. Carey, X. Zhu, and D. Melville. 1996. A biodiversity review of China. World Wildlife Fund International, Hong Kong, China.

Missouri Botanical Garden. 2005. Ethnobotanical plant conservation, Kawagebo Mountain, NW Yunnan. [online] URL:

http://www.mobot.org/MOBOT/research/yunnan/ yunnan intro.shtml.

McNeely, J. A. 1994. Lessons from the past: forests and biodiversity. Biodiversity and Conservation 3:3-20.

McNeely, J.A. 2000. Cultural factors in conserving biodiversity. Pages 128-142 in J. C. Xu, editor. Links between cultures and biodiversity: proceedings of the Cultures and Biodiversity Congress 2000, 20-30 July, Yunnan, China. Yunnan Sciences and Technology Press, Kunming, China.

Menzies, N. K. 1992. Strategic space: exclusion and inclusion in wildland policies in late imperial China. Modern Asian Studies 26:719-733.

Millennium Ecosystem Assessment. 2003. Ecosystems and human well-being: a frameworkfor assessment. Island Press, Washington, D.C., USA.

Mittermeier, R. A., P. R. Gil, M. Hoffman, J. Pilgrim, T. Brooks, C. G. Mittermeier, J. Lamoreux, and G. A. B. da Fonseca. 2005. Hotspots revisited: Earth's biologically richest and most endangered ecoregions. University of Chicago Press, Chicago, Illinois, USA.

Pei, S. J. 1985. Some effects of the Dai people's cultural beliefs and practices on the plant environment of Xishuangbanna, Yunnan Province, southwest China. Pages 321-339 in K. L. Hutterer, A. T. Rambo, and G. Lovelace, editors. Cultural 
values and human ecology in Southeast Asia. University of Michigan Press, Ann Arbor, Michigan, USA.

Pei, S. J., and P. Luo. 2000. Traditional culture and biodiversity conservation in Yunnan. Pages 143-153 in J. C. Xu, editor. Links between cultures and biodiversity: proceedings of the Cultures and Biodiversity Congress 2000, 20-30 July, Yunnan, China. Yunnan Sciences and Technology Press, Kunming, China.

Posey, D. A., and G. Dutfield. 1996. Beyond intellectual property: toward traditional resource rights for indigenous peoples and local communities. International Development Research Centre, Ottawa, Canada.

Rambo,A. T. 1995. The composite swidden system of the Tay and biodiversity in the mountains of northern Vietnam. Pages 69-89 in Proceedings of the Symposium on Montane Mainland Southeast Asia in Transition, Nov. 12-16, 1995. Chiang Mai University, Chang Mai, Thailand.

Ratner, B. D. 2000. Watershed governance: livelihoods and resource competition in the mountains of mainland Southeast Asia. Environmental Governance Note, June 2000. World Resources Institute, Washington, D.C., USA.

Sahlins, P., and J. C. Scott. 2001. Official and vernacular identifications in the making of the modern world. American Council for Learned Societies Collaborative Research Network. [online] URL:

http://www.acls.org/crn/network/doc july2001 summary. $\underline{\mathrm{htm}}$.

Sajise, P. E. 1995. Biodiversity and methods: a synthesis. Pages 277-281 in S. J.Pei and P. E. Sajise, editors. Regional study on biodiversity: concepts, frameworks, and methods. Yunnan University Press, Kunming, China.

Scott, J. 1998. Seeing like a state: how certain schemes to improve the human condition have failed. Yale University Press, New Haven, Connecticut, USA.

Shapiro, J. 2001. Mao's war against nature: politics and the environment in revolutionary China. Cambridge University Press, Cambridge, UK.
Sutherland, W. 2003. Parallel extinction risk and global distribution of languages and species. Nature 423:276-279.

Taveau, S., and W. Wang. 2005. Value of forest resources in a Miao community of Jindou Natural Village, Yunlong County, Yunnan Province. Centre for Biodiversity and Indigenous Knowledge, Kunming, China. [online] URL:

http://www.cbik.ac.cn/cbik-cn/cbik/our_work/download/ Valueofforest.pdf

Thompson, M., R. Ellis, and A. Wildavsky. 1990. Cultural theory. Westview Press, Boulder, Colorado, USA.

UNESCO. 2005. World heritage list. UNESCO Publishing, Paris, France. [online] URL:

http://whc.unesco.org/pg.cfm?cid=31.

Vavilov, N. I. 1992. Origin and geography of cultivated plants. Cambridge University Press, Cambridge, UK.

Wang, D. X. 2000. Heavy price to pay: a study on the relationship between social and environmental development in the Nujiang Canyon Region. Pages 622-632 in J. C. Xu, editor. Links between cultures and biodiversity: proceedings of the Cultures and Biodiversity Congress 2000, 20-30 July, Yunnan, China. Yunnan Sciences and Technology Press, Kunming, China.

Wang, J. H. 2000. Cultural practices and indigenous knowledge of swidden cultivation in Mengsong Akha Community, Xishuangbanna, Southwest China. Pages 633-639 in J. C. Xu, editor. Links between cultures and biodiversity: proceedings of the Cultures and Biodiversity Congress 2000, 20-30 July, Yunnan, China. Yunnan Sciences and Technology Press, Kunming, China.

Wang, J., and S. Chen. 2003. Indigenous knowledge on biodiversity conservation and management of Yi women: a case study in Chuxiong area, southwest China. Pages 189-192 in J. C. Xu and S. Mikesell, editors. Landscapes of diversity: proceedings of the III Symposium on MMSEA, 25-28 August 2002, Lijiang, China. Yunnan Sciences and Technology Press, Kunming, China.

Weyerhaeuser, H., A. Wilkes, and F. Kahrl. 2005. Local impacts and responses to regional forest conservation and rehabilitation programmes in 
China's northwest Yunnan Province. Agricultural Systems 86, in press.

Williams, D. M. 2002. Beyond great walls: environment, identity, and development on the Chinese grasslands of inner Mongolia. Stanford University Press, Stanford, California, USA.

Xu, J. C., and S. Mikesell. 2003. Indigenous knowledge for sustainable livelihoods and resource governance in the MMSEA region. Pages 3-22 in J. C. $\mathrm{Xu}$ and S. Mikesell, editors. Landscapes of diversity: proceedings of the III Symposium on MMSEA, 25-28 August 2002, Lijiang, China. Yunnan Sciences and Technology Press, Kunming, China.

Xu, J. C., and J. Ribot. 2004. Decentralization and accountability in forest management: case Studies from Yunnan, Southwest China. European Journal of Development Research. 16:153-173.

Xu, J. C., and M. Salas. 2003. Moving the periphery to the centre: indigenous people, culture and knowledge in a changing Yunnan. Pages 123-145 in M. Kaosa-ard and J. Dore, editors. Social challenges for the Mekong region. White Lotus, Bangkok, Thailand.

Xu, J. C., and A. Wilkes. 2004. Biodiversity impact analysis in northwest Yunnan, China. Biodiversity and Conservation 13:959-983.

Xu, J. C., J. Fox, X. Lu, N. Podger, S. Leisz, and X. H. Ai. 1999. Effects of swidden cultivation, state policies and customary institutions on land cover in a Hani village, Yunnan. Mountain Research and Development 19:123-132.

Xu, J. C., B. Li, and D. Waltner-Toews. 2004. Habitat of Tibetan nature and culture. EcoHealth 1:327-329.

Yang, F. Q. 2003. Mentorship of indigenous cultural specialists: a case study of training of Dongba, Naxi priests. Pages 479-485 in J. C. Xu and S. Mikesell, editors. Landscapes of diversity: proceedings of the III Symposium on MMSEA, 25-28 August 2002, Lijiang, China. Yunnan Sciences and Technology Press, Kunming, China.

Yang, Y., K. Tian, J. Hao, S. Pei, and Y. Yang. 2004. Biodiversity and biodiversity conservation in Yunnan, China. Biodiversity and Conservation 13-
:813-826.

Yin, S. 2001. People and forests: Yunnan swidden agriculture in human-ecological perspective. Yunnan Education Publishing House, Kunming, China. 